\title{
Cost-Effectiveness of Cardiac Resynchronization Therapy in Patients with Heart Failure in Thailand
}

This article was published in the following Dove Press journal:

ClinicoEconomics and Outcomes Research

\author{
Unchalee Permsuwan (iD) \\ Arintaya Phrommintikul ${ }^{2}$ \\ Voratima Silavanich ${ }^{1}$ \\ 'Department of Pharmaceutical Care, \\ Faculty of Pharmacy, Chiang Mai \\ University, Chiang Mai, Thailand; \\ ${ }^{2}$ Department of Internal Medicine, \\ Faculty of Medicine, Chiang Mai \\ University, Chiang Mai, Thailand
}

Background: Cardiac resynchronization therapy (CRT) improves symptoms and survival in patients with heart failure (HF). However, the CRT devices are costly and can impose a significant burden to the relatively constrained health budgets of middle-income countries such as Thailand. The aim of this study was to analyze the cost-effectiveness of CRT in combination with optimal medical therapy (OMT) relative to patients with OMT alone.

Methods: A two-component model was used to analyze lifetime costs and quality-adjusted life-years (QALYs) from a healthcare perspective. Clinical inputs were mostly obtained from meta-analysis of landmark trials. All cost-related data, risk of non-cardiovascular death and readmission rate were based on Thai HF data. Costs and QALYs were discounted at 3\%. Findings were reported as an incremental cost-effectiveness ratio (ICER). A variety of sensitivity analyses were also performed.

Results: CRT plus OMT costs more than OMT (123,279 vs 11,165 THB or 3,972.90 vs 359.81 USD), and is more effective (3.57 QALYs vs 2.49 QALYs), yielding an ICER of 104,325 THB per QALY (3,362.07 USD per QALY). CRT was cost-effective at the Thai willingness to pay threshold of 160,000 THB per QALY $(5,156.30$ USD per QALY). The results were sensitive to cost of CRT maintenance.

Conclusion: The use of CRT was associated with a cost-effectiveness ratio below generally accepted benchmarks for therapeutic interventions of 160,000 THB per QALY $(5,156.30$ USD per QALY). This suggests that the clinical benefits of CRT can be achieved at a reasonable cost in Thai HF patients.

Keywords: cost-effectiveness, quality-adjusted life-years, cardiac resynchronization therapy, heart failure, Thailand

\section{Introduction}

Heart failure (HF) is a global healthcare problem. In the United States, HF affects approximately 5.8 million people, with 870,000 new cases per year. ${ }^{1}$ In Asia, aging populations and large increases in cardiovascular risk factors have contributed to a high burden of $\mathrm{HF}^{2}$ In Thailand, among cardiovascular diseases, HF was the first leading cause of hospital admissions in 2015 . $^{3}$ Based on data of hospitalized patients with HF from three major Thailand reimbursement systems [Civil Servant Medical Benefit scheme (CS), Social Security scheme (SS), and Universal Coverage scheme (UC) systems], which accounted for more than $90 \%$ of Thai population, the study reports mortality rates of $11.0 \%, 24.5 \%, 32.5 \%$, and $46.3 \%$ for 1 month, 6 months, 1 year, and 3 years, respectively. ${ }^{4} \mathrm{HF}$ is associated with a significant socioeconomic burden, representing a major cause of hospitalization and readmissions, loss of work, and death. ${ }^{5,6}$ With the increasing use of neurohormonal antagonists, such as beta-blockers, angiotensin-
Correspondence: Voratima Silavanich Department of Pharmaceutical Care, Faculty of Pharmacy, Chiang Mai

University, Suthep Road, Muang District,

Chiang Mai 50200, Thailand

Tel +66 89-430-65I0

Fax +66 5-322-274I

Email voratima.silavanich@gmail.com 
converting enzyme inhibitors (ACEIs) and mineralocorticoid receptor antagonists (MRAs), the survival rate of $\mathrm{HF}$ with reduced ejection fraction (HFrEF) has improved markedly over the past decade. ${ }^{7}$ However, patients with severe symptoms may not respond to pharmacological treatment. CRT is indicated, with the highest recommendation level for symptomatic HF patients with broad QRS complex, LBBB QRS morphology and with left ventricular ejection fraction (LVEF) $\leq 35 \%$ despite optimal medical therapy (OMT) in order to improve symptoms and reduce morbidity and mortality, according to the current corresponding European and Thai guidelines. ${ }^{8,9}$ CRT is a well-established form of treatment that relies on two different treatment options: the biventricular pacemaker (CRT-P) and the cardiac biventricular defibrillator (CRT-D). Evidences from landmark randomized controlled trials and meta-analysis show a reduction of all-cause mortality and hospitalizations and an improvement in New York Heart Association (NYHA) classes and quality-of-life for both the CRT-P and CRT-D. ${ }^{10-14}$ However, the CRT devices are quite expensive and can impose a significant burden to the relatively constrained health budgets of the middle-income countries, ${ }^{15}$ especially in Thailand. Therefore, economic evaluation of a costly intervention has become useful evidence for decision-makers to decide whether it is good value for money. Several trials showed that CRT was cost-effective for HF patients in the upper-income countries. ${ }^{16-19}$ However, much less is known about the cost-effectiveness of CRT in the Thai HF population. Hence, we conducted a cost-effectiveness study of CRT in Thai HF patients, using a combined model between decision tree and Markov model to estimate the incremental cost-effectiveness ratio (ICER) of adding CRT to the OMT.

\section{Methods}

\section{Model Description}

The model is composed of two components. The shortterm component is a decision tree (Figure 1A), representing the costs and consequences of the 1-month period for initial device implantations. The second component is a state-transition Markov model (Figure 1B and C), representing the long-term costs and consequences of the hypothetical cohort for the lifetime horizon.

The model evaluates CRT in combination with OMT compared with OMT alone. Patients with HF enter the decision tree model undergoing CRT implantation surgery or receive OMT. Those undergoing the surgery may experience procedure-related mortality or survive the implantation procedure. Patients who survive the procedure may have successful or unsuccessful implantation. Patients with a successful CRT implantation can become stable state, or experience some complications such as perioperative complications, lead displacement, or infection. In case of unsuccessful implantation, patients would return to being managed with OMT alone. The OMT Markov model is composed of three health states: stable HF, hospitalization, and death (cardiovascular death and non-cardiovascular death). Patients with HF who receive OMT enter the Markov model in a stable health state. They may remain stable or be hospitalized because of HF, or death in the next cycle. OMT patients who are hospitalized can return to the stable health state after treatment. The CRT Markov model is composed of four health states: stable HF, complications (infection and lead displacement), hospitalization, and death (cardiovascular death and non-cardiovascular death). Patients with HF who have successful CRT implantation enter the Markov model in a stable health state. The next cycle, they can remain as stable or move to other health states such as hospitalization because of $\mathrm{HF}$, or complications which require hospitalization, or death from either cardiovascular or non-cardiovascular causes. The model followed patients over their lifetime with a 1-month cycle. The long-term costs, life-years, and quality-adjusted life-years (QALYs) were estimated using Microsoft Excel.

\section{Target Population}

The target population was patients with HF with ejection fraction $\leq 35 \%$, in NYHA class III or IV, and with prolonged QRS interval on electrocardiogram. This profile represents the same patient characteristics as the cohort included in the Comparison of Medical Therapy, Pacing, and Defibrillation in Heart Failure (COMPANION) trial. ${ }^{11}$ All patients in the hypothetical cohort enter the model with 65 years of age because this is the age at which patients are classified as elderly in the Thai HF database. ${ }^{4}$ The cohort population would receive either the OMT alone or the CRT in combination with OMT. The OMT includes diuretics, ACEIs, beta blockers, and MRAs. The CRT in this study is pacemaker type (CRT-P).

\section{Input Parameters}

Probabilities of Short-Term Decision Tree Model

\section{Perioperative Complications}

The probability of patients undergoing CRT implantation was obtained from the study by Fox et al. ${ }^{20}$ This study reports a pooled risk of complications from the Cardiac 

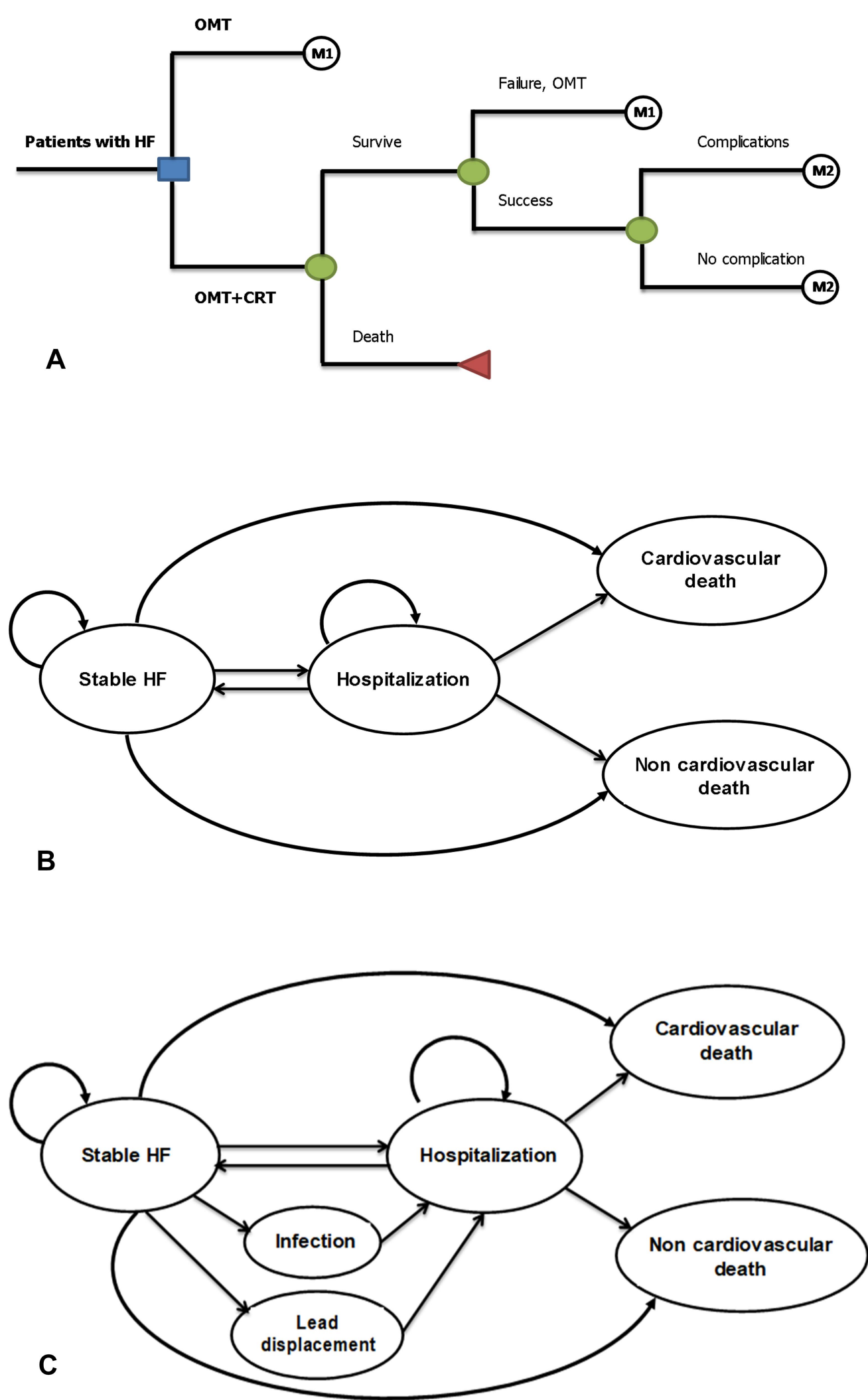

Figure I (A) Short-term decision tree. (B) Long-term Markov model for optimal medical therapy. (C) Long-term Markov model for cardiac-resynchronization therapy. Abbreviations: CRT, cardiac resynchronization therapy; HF, heart failure; OMT, optimal medical therapy. 
Resynchronization-Heart Failure (CARE-HF) trial, the Multicenter InSync Randomized Clinical Evaluation (MIRACLE) trial, the Multisite Stimulation in Cardiomyopathy (MUSTIC) trial, the COMPANION trial, and the VENTAK ${ }^{\circledR}$ CHF/CONTAK ${ }^{\circledR}$ CD/ EASYTRAK $®$ Biventricular Pacing Study (CONTAKCD) trial. A probability of perioperative complication of 0.1063 was used in this study.

\section{Perioperative Death}

We obtained the probability of death from CRT implantation from the study by Colquitt et al. ${ }^{21}$ This study pooled the number of events reported in the CRT group from the CARE-HF, MIRACLE, MUSTIC, and COMPANION trials. A probability of perioperative death was 0.0048 .

\section{Implant Failure}

The probability of implant failure for patients who underwent CRT implantation was estimated based on the four clinical trials (CARE-HF, MIRACLE, MUSTIC, COMPANION). A pooled probability of implant failure was equal to $0.084 .^{21}$

\section{Probabilities of Long-Term Markov Model Cardiovascular Mortality}

Cardiovascular (CV) mortality risks were derived from the COMPANION trial. ${ }^{11}$ Of the total 308 OMT patients, 58 $(18.83 \%)$ died from cardiovascular cause after a median follow-up of 11.9 months. This probability was converted to a $1-$ month rate using the formula $r=-[\ln (1-p)] / t$, where $\mathrm{p}$ is probability, $r$ is rate, and $t$ is duration. It was subsequently converted back to 1-month probability using the formula $\mathrm{p}=1-\exp ^{\wedge}(-\mathrm{rt})$, where $\mathrm{p}$ is probability, $\mathrm{r}$ is rate, and $\mathrm{t}$ is duration. The 1-month probability of $\mathrm{CV}$ death in the OMT group was 0.0174 . The relative effect of CRT on HF deaths was obtained from the meta-analysis encompassing the findings from the CARE-HF trial and the COMPANION trial. The pooling estimate of relative risk (RR) was $0.67 .^{21}$ The CV death of CRT patients was the product of this relative effect and the $\mathrm{CV}$ death of OMT patients. As a result, 1-month probability of $\mathrm{CV}$ death in the CRT group was 0.0117. Then, we calculated the CV death rate in hospital and non-hospital settings. Based on the HF mortality database in Thailand, ${ }^{4} \mathrm{HF}$ patients aged $\geq 65$ years had annual risk of in-hospital CV mortality equal to $9.37 \%$. Therefore, the in-hospital CV mortalities of the OMT and CRT patients were 0.00014 and 0.00010 , respectively. Risk of $\mathrm{CV}$ death in non-hospital was the difference of the overall $\mathrm{CV}$ death and the $\mathrm{CV}$ death in hospital. This leads to the risk of CV death in non-hospital for the OMT and CRT patients of 0.0172 and 0.0116 , respectively.

\section{Non-Cardiovascular Mortality}

We relied on data from the Thai database. ${ }^{4}$ Of the total 201,709 admitted HF patients, 19,238 (9.54\%) died from non-CV death per year. This figure was converted to 1month probability (0.0083). We assumed equal risk of non-CV mortality for the OMT and CRT patients.

\section{Hospital Admission Because of Heart Failure}

The baseline risk of hospital admission was obtained from the study by Colquitt et al, ${ }^{21}$ which pooled the estimate from the number of events reported for the OMT arm in the CARE-HF, MIRACLE, MUSTIC, and COMPANION trials. The baseline risk of hospitalization was 0.037 . Then, we calculated the risk of hospitalization for the CRT group by multiplying the baseline risk with the relative risk of 0.58. After discharge from the hospital, patients are able to readmit within 30 day. The readmission rate of $34 \%$ was obtained from the Thai HF national database. ${ }^{22}$ It was converted to risk of readmission from any cause at 30 days which was equal to 0.2882 .

\section{Complications}

We included infection and lead displacement as complications that could occur in the Markov model. The risk of complications was derived from the clinical trials included in the systematic review of cost-effectiveness study. ${ }^{21}$ Probabilities of 0.0006 and 0.0037 were used for devicerelative infection and lead displacement in the CRT group, respectively.

\section{Utility}

Since there is a paucity of utility data in Thailand, we relied on data from a literature review. Utilities of HF with stable and hospitalization were 0.750 and 0.650 , respectively. ${ }^{23}$ A utility of CRT implantation of 0.460 in the short-term model was included. Disutility of 0.10 for infection was also counted in the analysis.

\section{Costs}

Since this study considered provider's perspective, only direct medical costs were included. Those composed of costs of CRT, OMT, hospitalization, and complication treatment. We assumed that the battery for CRT patients needed maintenance every 10 years. Its maintenance cost 
half of the cost of CRT implantation. We obtained cost data from the hospital database of patients with HF who underwent CRT implantation from 2010 to 2018 at Maharaj Nakorn Chiang Mai hospital, the largest hospital in the north of Thailand. Hospitalization cost in this study was obtained from a previous study which collected data from the same hospital. ${ }^{24}$ All cost inputs were the average costs and are shown in Table 1. All costs were inflated using the consumer price index (CPI) in medical care category and presented in 2019. The exchange rate of 31.03 THB per USD was used in this study. ${ }^{25}$

\section{Study Analyses \\ Base-Case Analysis}

Future costs and outcomes were discounted at an annual rate of $3 \%$, in accordance with the Thai Health Technology Assessment guideline. ${ }^{26}$ The ICER was the ratio of the difference in total costs and the difference in effect between CRT and OMT patients. The ICER results were presented as an ICER in THB (USD) per life-year (LY), and an ICER in THB (USD) per quality-adjusted life-year (QALY). The CRT intervention would be justified costeffective when the estimated ICER is lower than the local threshold of 160,000 THB per QALY (5,156.30 USD per QALY) or about 1.2-times per capital gross national income. $^{27}$

\section{Sensitivity Analyses}

We performed one-way sensitivity analyses to assess the uncertainty associated with deterministic parameters in our model. All 27 variables were varied within the plausible range. If the $95 \%$ confidence interval was available, we used it as a plausible range. If not, the range of $\pm 20 \%$ or $\pm 10 \%$ was used for cost and probability, respectively. A Tornado diagram was plotted to demonstrate the impact of selected inputs on the ICER outputs.

Probabilistic sensitivity analyses were also performed to evaluate the combined effects of uncertainty in all model inputs. The specific distribution was assigned to input parameters. For example, beta distribution was for probability and utility estimates, gamma distribution was for costs, log normal distribution was for relative effect. A thousand iterations of random samples were performed. The result was shown as a scatterplot on the cost-effectiveness plane. A cost-effectiveness acceptability curve (CEAC) was also plotted to show the probability of CRT alternative to be cost-effective at various willingness-topay thresholds.

\section{Results}

\section{Base-Case Result}

Table 2 shows the findings of the study. As expected, the CRT alternative had higher cost than the OMT alternative (123,279 vs 11,165 THB) $(3,972.90$ vs 359.81 USD), but the CRT alternative gained more LY and QALY than the OMT alternative (4.81 vs 3.34 LY; 3.57 vs 2.49 QALY). This yielded an ICER of 76,632 THB per LY $(2,469.61$ USD per LY), and 104,325 THB per QALY (3,362.07 USD per QALY). The estimated ICER was below the local Thai threshold of 160,000 THB per QALY (5,156.30 USD per QALY). In addition, the number of $\mathrm{CV}$ deaths from the CRT alternative was lower than those from the OMT alternative (513 vs 723 for 1,000 cohort HF population).

\section{Sensitivity Analysis Results}

The Tornado diagram (Figure 2) shows the effect of altering input parameters within the plausible ranges. Of all 27 variables varied within specified ranges, cost of CRT maintenance showed the greatest impact on ICER, followed by the risk of $\mathrm{CV}$ from non-hospitalization in the OMT patients, RR of the CV death, and so on. The scatter plot diagram (Figure 3) shows that all ICERs of 1,000 iterations fell on the upper right quadrant. This means that the CRT alternative incurs higher cost, but provides more life-year gained, and QALY gained than the OMT alternatives. At the willingness to pay of 160,000 THB per QALY (5,156.30 USD per QALY), the probability of the CRT alternative being cost-effective was about $98.5 \%$ (Figure 4).

\section{Discussion}

We conducted the first cost-effectiveness study using an analytical model to examine whether the CRT for HF treatment from a healthcare payer perspective was costeffective in Thailand. The finding of the study indicated ICER of 104,325 THB per QALY (3,362.07 USD per QALY), which was justified cost-effective compared to the local threshold of 160,000 THB per QALY $(5,156.30$ USD per QALY). The result was confirmed with the findings from probabilistic sensitivity analysis (PSA). All thousand iterations fell on the upper right quadrant, indicating higher cost but gaining better QALY of CRT alternative compared with the OMT. This yielded $98.5 \%$ of the CRT alternative being cost-effective. The estimated ICER was sensitive to cost of CRT maintenance. We believe that 
Table I Input Parameters Used in the Model

\begin{tabular}{|c|c|c|c|}
\hline Parameters & \multirow[t]{2}{*}{ Value } & \multirow[t]{2}{*}{ Range } & \multirow[t]{2}{*}{ Reference } \\
\hline Probabilities Used in the Model & & & \\
\hline \multicolumn{4}{|l|}{ Short-term model } \\
\hline Death & 0.0048 & $0.0015-0.0081$ & Colquitt et $\mathrm{al}^{2 \mathrm{I}}$ \\
\hline Failure & 0.0840 & $0.0700-0.0970$ & Colquitt et $\mathrm{al}^{21}$ \\
\hline Complication & 0.1063 & $0.0957-0.1169$ & Fox et $\mathrm{al}^{20}$ \\
\hline \multicolumn{4}{|l|}{ Long-term model } \\
\hline Risk of CV mortality & 0.0174 & & Bristow et al ${ }^{11}$ \\
\hline $\begin{array}{l}\text { Relative risk of } C V \text { death } \\
\text { (CRT vs OMT) }\end{array}$ & 0.67 & $0.51-0.88$ & Colquitt et $\mathrm{al}^{21}$ \\
\hline Risk of CV death from hospitalization & 0.0001 & $0.000 \mathrm{I}-0.0002$ & Calculation \\
\hline \multicolumn{4}{|l|}{$\mathrm{CRT}^{\mathrm{b}}$} \\
\hline Risk of CV death from non-hospitalization & 0.0172 & $0.0155-0.0190$ & Calculation \\
\hline \multicolumn{4}{|l|}{$\mathrm{CRT}^{\mathrm{d}}$} \\
\hline Risk of non-CV death from hospitalization & 0.0083 & $0.0075-0.0091$ & Krittayaphong et $\mathrm{al}^{4}$ \\
\hline Risk of non-CV death from non-hospitalization & & & Burden of disease in Thai population ${ }^{35}$ Health statistics ${ }^{36}$ \\
\hline 65 & & 0.0052 & \\
\hline 70 & & 0.0080 & \\
\hline 75 & & 0.0128 & \\
\hline 80 & & 0.0203 & \\
\hline 85 & & 0.0357 & \\
\hline 90 & & 0.0357 & \\
\hline 95 & & 0.0357 & \\
\hline 100 & & 0.0357 & \\
\hline Risk of hospitalization OMT & 0.037 & $0.025-0.049$ & Colquitt et $\mathrm{al}^{2 \mathrm{I}}$ \\
\hline Risk of all-cause 30 -day readmission & 0.2882 & $0.2594-0.317 \mid$ & Thailand database ${ }^{22}$ \\
\hline Risk of infection & 0.0006 & $0-0.0020$ & Colquitt et $\mathrm{al}^{21}$ \\
\hline Risk of lead displacement & 0.0037 & $0.0033-0.0041$ & Colquitt et $\mathrm{al}^{21}$ \\
\hline $\begin{array}{l}\text { Relative risk of hospitalization } \\
\text { (CRT vs OMT) }\end{array}$ & 0.58 & $0.35-0.96$ & Colquitt et $\mathrm{al}^{21}$ \\
\hline \multicolumn{4}{|l|}{ Costs (THB/USD per cycle) } \\
\hline CRT & $\begin{array}{l}367,710 \\
(11,850.15)\end{array}$ & $\begin{array}{l}294,168-441,252 \\
(9,480.12-14,220.17)\end{array}$ & Hospital database ${ }^{23}$ \\
\hline OMT & $\begin{array}{l}3,048 \\
(98.23)\end{array}$ & $\begin{array}{l}2,438-3,658 \\
(78.57-117.89)\end{array}$ & \\
\hline Hospitalization & $\begin{array}{l}10,518 \\
(338.96)\end{array}$ & $\begin{array}{l}8,414-12,621 \\
(271.16-406.74)\end{array}$ & \\
\hline Infection & $\begin{array}{l}47,062 \\
(1,516.66)\end{array}$ & $\begin{array}{l}37,650-56,474 \\
(1,213.34-1,819.98)\end{array}$ & \\
\hline Lead displacement & $\begin{array}{l}10,518 \\
(338.96)\end{array}$ & $\begin{array}{l}8,4|4-12,62| \\
(27 \mid .16-406.74)\end{array}$ & \\
\hline Perioperative complications & $\begin{array}{l}32,000 \\
(1,031.26)\end{array}$ & $\begin{array}{l}25,600-38,400 \\
(825.01-1,237.51)\end{array}$ & \\
\hline \multicolumn{4}{|l|}{ Utilities } \\
\hline HF stable & 0.750 & $0.675-0.825$ & Adena et $\mathrm{al}^{23}$ \\
\hline Hospitalization & 0.650 & $0.585-0.715$ & Adena et $\mathrm{al}^{23}$ \\
\hline CRT implantation & 0.460 & $0.414-0.506$ & Neyt et $\mathrm{al}^{37}$ \\
\hline Disutility of infection & 0.1 & $0.09-0.11$ & Colquitt et $\mathrm{al}^{21}$ \\
\hline
\end{tabular}

Notes: ${ }^{\mathrm{a}} \mathrm{I}$-month rate of CV death from COMPANION trial $=-(\ln (\mathrm{I}-18.83 \%)) / \mathrm{I}$ I.9=I.75\%; I-month rate of CV death in hospital in Thailand $=-(\mathrm{In}(\mathrm{I}-9.73 \%)) / \mathrm{I} 2=0.82 \%$; I-month rate of $C V$ death in hospital in this study $=-(\ln (I-9.73 \%)) / 12=1.75 \% * 0.82 \%=0.01 \%$; Probability of $C V$ death in hospital $=1-\exp (-0.01 \%)=0.0001$; ${ }^{b} \mathrm{I}-\mathrm{month}$ rate of $\mathrm{CV}$ death from COMPANION trial $=1.75 \% * 0.67=1.17 \%$ (HR 0.67); I-month rate of CV death in hospital in Thailand $=-(\ln (I-9.73 \%)$ )/ I $2=0.82 \%$; I-month rate of CV death in hospital in this study $=1.17 \% * 0.82 \%=0.01 \%$; Probability of CV death in hospital $=1-\exp (-0.01 \%)=0.000 \mathrm{I} ;{ }^{C} \mathrm{I}$-month probability of CV death $=1$-exp $(-1.75 \%)=0.017$; I-month probability of CV death from non-hospitalization $=0.017-0.000 \mathrm{I}=0.0172 ;{ }^{\mathrm{d}} \mathrm{I}$-month probability of $\mathrm{CV}$ death $=\mathrm{I}-\exp (-\mathrm{I} . \mathrm{I} \% \mathrm{~F})=0.0 \mathrm{I} 2$; $\mathrm{I}$-month probability of $\mathrm{CV}$ death from non-hospitalization $=0.0 \mathrm{I} 2-$ $0.000 \mathrm{I}=0.0116$.

Abbreviations: CRT, cardiac resynchronization therapy; CV, cardiovascular; OMT, optimal medical therapy; HR, hazard ratio; HF, heart failure; THB, Thai baht; USD, United States dollars. 
Table 2 Base-Case Result

\begin{tabular}{|c|c|c|c|c|c|}
\hline \multirow[t]{2}{*}{ Treatment } & \multirow{2}{*}{$\begin{array}{l}\text { Total Cost } \\
\text { (THB/USD) }\end{array}$} & \multirow{2}{*}{$\begin{array}{l}\text { Life-Year } \\
\text { (Years) }\end{array}$} & \multirow[t]{2}{*}{ Quality-Adjusted Life-Years } & \multicolumn{2}{|l|}{ ICER } \\
\hline & & & & $\begin{array}{l}\text { THB/LY } \\
\text { (USD/LY) }\end{array}$ & $\begin{array}{l}\text { THB/QALY } \\
\text { (USD/QALY) }\end{array}$ \\
\hline CRT & $\begin{array}{l}123,279 \\
(3,972.90)\end{array}$ & 4.81 & 3.57 & \multirow[t]{2}{*}{$\begin{array}{l}76,632 \\
(2,469.61)\end{array}$} & \multirow[t]{2}{*}{$\begin{array}{l}104,325 \\
(3,362.07)\end{array}$} \\
\hline OMT & $\begin{array}{l}11,165 \\
(359.81)\end{array}$ & 3.34 & 2.49 & & \\
\hline
\end{tabular}

Abbreviations: CRT, cardiac resynchronization therapy; OMT, optimal medical therapy; ICER, incremental cost-effectiveness ratio; LY, life-year; QALY, quality-adjusted lifeyear; THB, Thai baht; USD United States dollars.

the findings of our study are the useful economic evidence to confirm the decision of health policy-makers to broaden the health benefit of this device to Thai HF patients. Our findings might also generalize to HF patients in other countries that have healthcare systems like Thailand, but having limited local economic evidence available.

When comparing our results with other cost-effectiveness analyses, we found that the mean cost per each QALY is lower than those found in other countries, like the US and Spain. ${ }^{16,19,28}$ This might be due to the fact that the costs of HF hospitalization, CRT management, and complication treatment in Thailand are lower than those incurred in the upper-income countries. However, CRT alternatives in several countries are still cost-effective because the estimated ICER were below the threshold used in each country.
Despite OMT, refractory HF is a common occurrence. The emergence of CRT has brought a new paradigm in the management of HF. ${ }^{29}$ CRT is one of the most promising device therapies in HF, improving the prognosis of $\mathrm{HF}$, and incorporating into therapeutic guidelines. ${ }^{30}$ In a series of trials, CRT improved symptoms, exercise capacity, the quality-of-life, ventricular function, mortality, and HF hospitalization in HF populations. ${ }^{10,12,13,31,32}$ Effective pacing leads to a lower number of $\mathrm{HF}$ hospitalizations, thus allowing significant cost offsets in the US setting. ${ }^{33}$ In Asian settings, there were substantial variations in healthcare spending, and the average cost of HF hospitalization varied from 813 USD to nearly 9,000 USD. ${ }^{24}$ The cost of HF hospitalization in Thailand is 3,600 USD. ${ }^{24}$ However, CRT is not widely used in treatment of HF in East Asia,

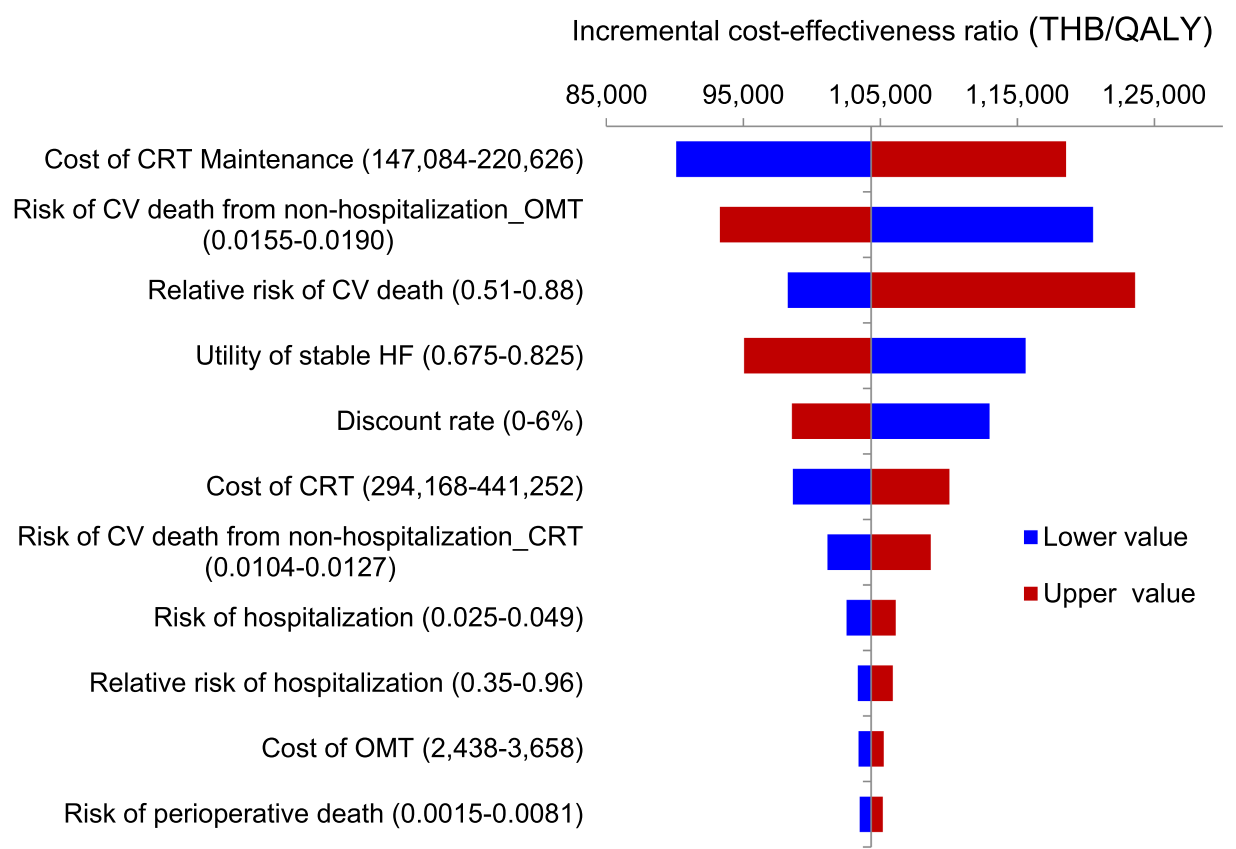

Figure 2 Tornado diagram of cardiac resynchronization therapy in combination with optimal medical therapy compared with optimal medical therapy alone. Abbreviations: CRT, cardiac resynchronization therapy; CV, cardiovascular; OMT, optimal medical therapy; HF, heart failure; THB, Thai baht; QALY, quality-adjusted life-year. 


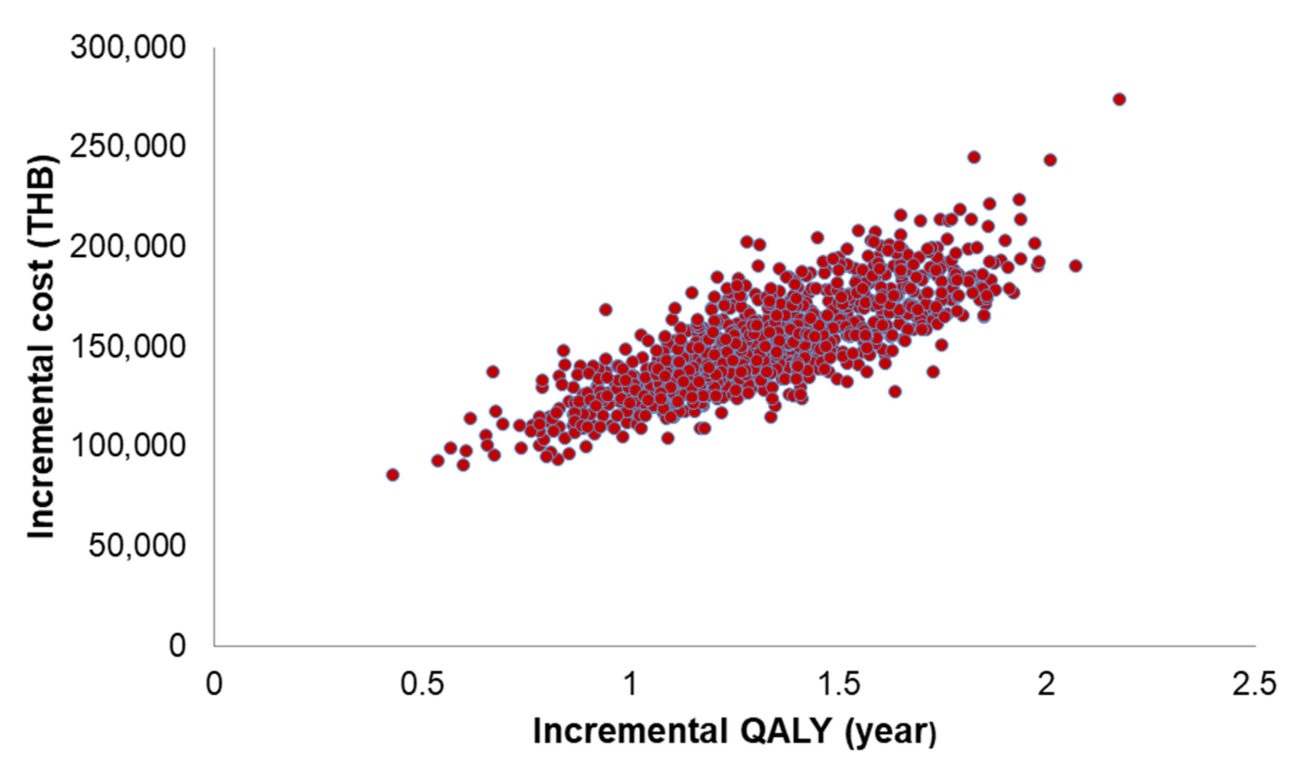

Figure 3 Scatter plot of probabilistic sensitivity analysis.

Abbreviations: THB, Thai baht; QALY, quality-adjusted life-year.

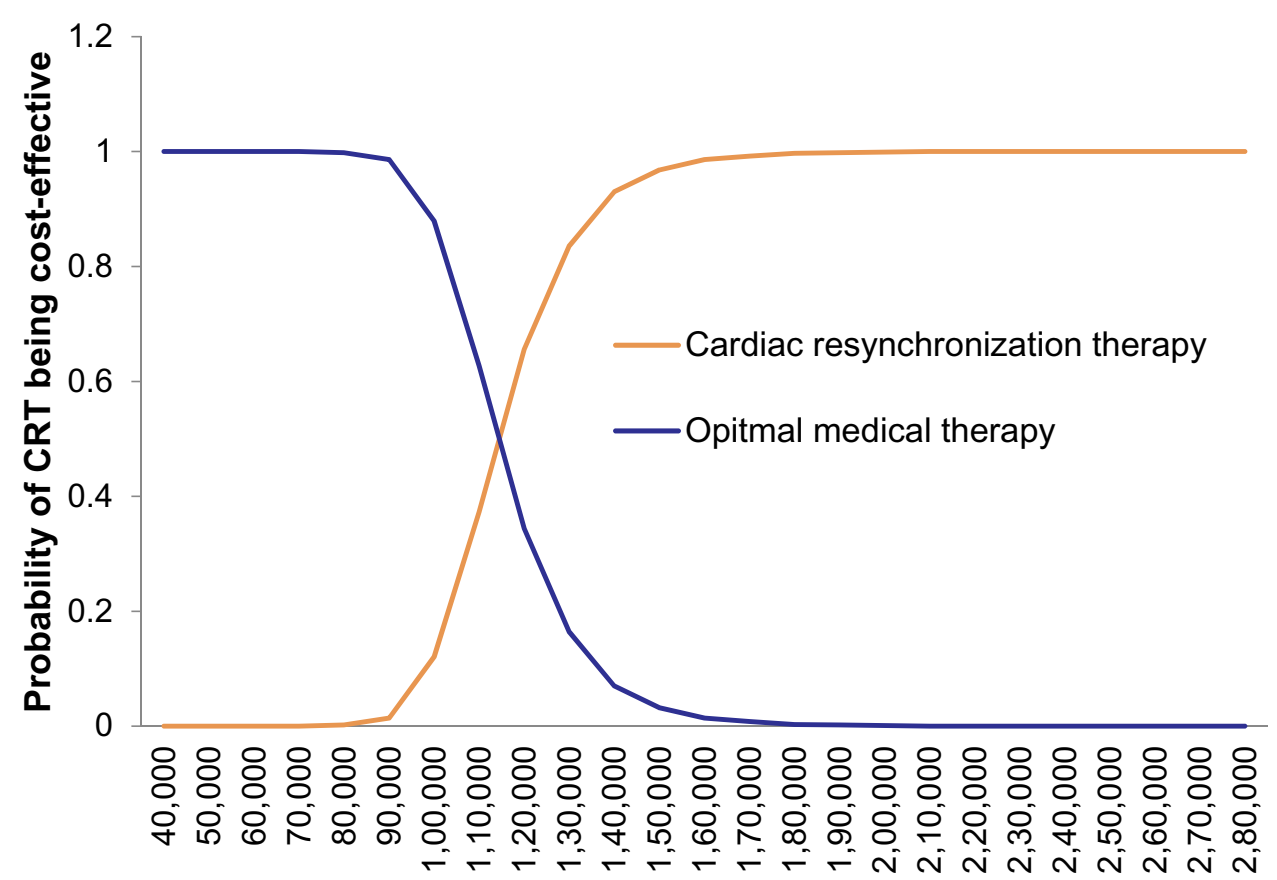

Willngness to pay (THB/QALY)

Figure 4 Cost-effectiveness acceptability curve of cardiac resynchronization therapy in combination with optimal medical therapy compared with optimal medical therapy alone. Abbreviations: THB, Thai baht; QALY, quality-adjusted life-year.

including Thailand. ${ }^{34}$ The findings of this study would generate economic evidence for decision-makers to justify an increase in CRT use for HF patients.

The following limitations should be noted: First, the economic evaluations are limited by the external validity of the trial results. The technical skills of providers, patient selection and differences in the optimal treatment regimen may vary in real-world practice and affect the clinical effectiveness of the therapy. We tried to address this limitation by incorporating data from the Thai database such as $\mathrm{CV}$ death, non-CV death, age-specific mortality rate, and cost data. Second, our study only shows the results of 
CRT-P, not including CRT-D. CRT-P is widely used in Thailand because of the simple accessibility and low cost. In addition, CRT-P can be used in cases of sudden cardiac death, whereas CRT-D cannot be used in this situation. CRT-P can also reduce ventricular arrhythmia and reverse cardiac remodeling. Finally, cost data were obtained from one large tertiary hospital in the North of Thailand. This might not represent the cost data from all hospitals in Thailand. Since CRT-P treatment can be performed only in the tertiary care levels with cardiologists available, only small numbers of hospitals can do this operation in Thailand. Therefore, we believe that our cost data should not be much different from other tertiary care hospitals outside Bangkok. However, our analysis has several potential strengths. The effectiveness estimates incorporated into the decision analysis were based on meta-analysis and high-quality randomized controlled trials. The parameters, including the confidence interval used for sensitivity analysis, from those studies were used in the model. In addition, our model reflects both shortterm and long-term outcomes from a decision tree and Markov model, respectively.

\section{Conclusion}

This cost-effectiveness analysis indicates that the clinical benefits of CRT are economically viable and can be achieved at a reasonable cost. Long-term treatment with CRT in combination with OMT appears to be cost-effective compared with OMT alone in Thailand within the local threshold of 160,000 THB per QALY $(5,156.30$ USD per QALY).

\section{Disclosure}

The authors report no conflicts of interest in this work.

\section{References}

1. Mozaffarian D, Benjamin EJ, Go AS, et al. Heart disease and stroke statistics-2016 update: a report from the American heart association. Circulation. 2016;133(4):e38-360.

2. Shimokawa H, Miura M, Nochioka K, Sakata Y. Heart failure as a general pandemic in Asia. Eur J Heart Fail. 2015;17(9):884-892. doi:10.1002/ejhf.319

3. Summary report of morbidity A.D.2015. Bureau of policy and strategy MoP, editor. Bangkok: Samcharoen Panich; 2016.

4. Krittayaphong R, Karaketklang K, Yindeengam A, Janwanishstaporn S. Heart failure mortality compared between elderly and non-elderly Thai patients. J Geriatr Cardiol. 2018;15(12):718-724.

5. Kim SJ, Park EC, Kim TH, Yoo JW, Lee SG. Mortality, length of stay, and inpatient charges for heart failure patients at public versus private hospitals in South Korea. Yonsei Med J. 2015;56(3):853-861. doi:10.3349/ymj.2015.56.3.853
6. Robertson J, McElduff P, Pearson S-A, Henry DA, Inder KJ, Attia JR. The health services burden of heart failure: an analysis using linked population health data-sets. BMC Health Serv Res. 2012;12:103. doi:10.1186/1472-6963-12-103

7. Teng TK, Tromp J, Tay WT, et al. Prescribing patterns of evidencebased heart failure pharmacotherapy and outcomes in the ASIAN-HF registry: a cohort study. Lancet Glob Health. 2018;6(9):e1008-e1018. doi:10.1016/S2214-109X(18)30306-1

8. Ponikowski P, Voors AA, Anker SD, et al. 2016 ESC Guidelines for the diagnosis and treatment of acute and chronic heart failure: the task force for the diagnosis and treatment of acute and chronic heart failure of the European society of cardiology (ESC) developed with the special contribution of the Heart Failure Association (HFA) of the ESC. Eur Heart J. 2016;37(27):2129-2200.

9. Chantrarat T, Yingchoncharoen T, Kanjanavanich R, Kanjanavanich R, Ayudhya R, Porapakkham P. Heart Failure Council of Thailand (HFCT) 2019 heart failure guideline: sudden cardiac death and device therapy in heart failure. J Med Assoc Thai. 2019;102(5):618-622.

10. Cleland JG, Daubert JC, Erdmann E, et al. The effect of cardiac resynchronization on morbidity and mortality in heart failure. $N$ Engl $J$ Med. 2005;352(15):1539-1549. doi:10.1056/NEJMoa050496

11. Bristow MR, Saxon LA, Boehmer J, et al. Cardiac-resynchronization therapy with or without an implantable defibrillator in advanced chronic heart failure. $N$ Engl J Med. 2004;350(21):2140-2150. doi:10.1056/NEJMoa032423

12. Abraham WT, Fisher WG, Smith AL, et al. Cardiac resynchronization in chronic heart failure. N Engl J Med. 2002;346(24):1845-1853. doi:10.1056/NEJMoa013168

13. Auricchio A, Stellbrink C, Sack S, et al. Long-term clinical effect of hemodynamically optimized cardiac resynchronization therapy in patients with heart failure and ventricular conduction delay. $J \mathrm{Am}$ Coll Cardiol. 2002;39(12):2026-2033. doi:10.1016/S0735-1097(02) 01895-8

14. Bradley DJ, Bradley EA, Baughman KL, et al. Cardiac resynchronization and death from progressive heart failure: a meta-analysis of randomized controlled trials. JAMA. 2003;289(6):730-740. doi:10.1001/jama.289.6.730

15. Bertoldi EG, Rohde LE, Zimerman LI, Pimentel M, Polanczyk CA. Cost-effectiveness of cardiac resynchronization therapy in patients with heart failure: the perspective of a middle-income country's public health system. Int $J$ Cardiol. 2013;163(3):309-315. doi:10.1016/j.ijcard.2011.06.046

16. Feldman AM, de Lissovoy G, Bristow MR, et al. Cost effectiveness of cardiac resynchronization therapy in the comparison of medical therapy, pacing, and defibrillation in heart failure (COMPANION) trial. $J$ Am Coll Cardiol. 2005;46(12):2311-2321. doi:10.1016/j.jacc.2005.08.033

17. Callejo D, Guerra M, Hernández-Madrid A, Blasco JA. Economic assessment of cardiac resynchronization therapy. Rev Esp Cardiol. 2010;63(11):1235-1243. doi:10.1016/S0300-8932(10)70293-1

18. Aidelsburger P, Grabein K, Klauss V, Wasem J. Cost-effectiveness of cardiac resynchronization therapy in combination with an implantable cardioverter defibrillator (CRT-D) for the treatment of chronic heart failure from a German health care system perspective. Clin Res Cardiol. 2008;97(2):89-97. doi:10.1007/s00392-007-0586-9

19. Shah D, Lu X, Paly VF, Sintzos SI, May DM. Cost-effectiveness analysis of implantable cardiac devices in patients with systolic heart failure: a US perspective using real world data. J Med Econ. 2020;23 (7):690-697. doi:10.1080/13696998.2020.1746316

20. Fox M, Mealing S, Anderson R, et al. The clinical effectiveness and cost-effectiveness of cardiac resynchronisation (biventricular pacing) for heart failure: systematic review and economic model. Health Technol Assess. 2007;11(47):iii-iv, ix-248. doi:10.3310/hta11470

21. Colquitt JL, Mendes D, Clegg AJ, et al. Implantable cardioverter defibrillators for the treatment of arrhythmias and cardiac resynchronisation therapy for the treatment of heart failure: systematic review and economic evaluation. Health Technol Assess. 2014;18(56). 
22. Janwanishstaporn S. National trend, in-hospital and long term outcomes in the hospitalized heart failure patients in Thailand. Thai Heart J. 2015;28:128.

23. Adena MA, Hamann G, Sindone AP. Cost-effectiveness of ivabradine in the treatment of chronic heart failure. Heart Lung Circ. 2019;28 (3):414-422. doi:10.1016/j.hlc.2018.01.011

24. Reyes EB, Ha JW, Firdaus I, et al. Heart failure across Asia: same healthcare burden but differences in organization of care. Int $J$ Cardiol. 2016;223:163-167. doi:10.1016/j.ijcard.2016.07.256

25. Bank of Thailand. Foreign exchange rates. 2020 [cited June 15, 2020]. Available from: https://www.bot.or.th/english/statistics/finan cialmarkets/exchangerate/_layouts/application/exchangerate/ ExchangeRate.aspx.

26. Permsuwan U, Guntawongwan K, Buddhawongsa P. Handling time in economic evaluation studies. J Med Assoc Thai. 2014;97(Suppl 5): S50-58.

27. Limwattananon S. Sensitivity analysis for handling uncertainty in an economic evaluation. In: Chaikledkaew U, Teerawattananon Y, editors. Guidelines for Health Technology Assessment in Thailand. 2nd ed. Nonthaburi: Wacharin; 2013:105-119.

28. Calvert MJ, Freemantle N, Yao G, et al. Cost-effectiveness of cardiac resynchronization therapy: results from the CARE-HF trial. Eur Heart J. 2005;26(24):2681-2688. doi:10.1093/eurheartj/ehi662

29. Fang F, Jie ZY, Xia LX, et al. Cardiac resynchronisation therapy and heart failure: persepctive from 5P medicine. Card Fail Rev. 2015;1 (1):35-37. doi:10.15420/CFR.2015.01.01.35

30. Normand C, Linde C, Singh J, Dickstein K. Indications for cardiac resynchronization therapy. JACC Heart Fail. 2018;6(4):308.
31. Higgins SL, Hummel JD, Niazi IK, et al. Cardiac resynchronization therapy for the treatment of heart failure in patients with intraventricular conduction delay and malignant ventricular tachyarrhythmias. J Am Coll Cardiol. 2003;42(8):1454-1459. doi:10.1016/S0735-1097 (03)01042-8

32. Linde C, Leclercq C, Rex S, et al. Long-term benefits of biventricular pacing in congestive heart failure: results from the MUltisite STimulation in cardiomyopathy (MUSTIC) study. $J$ Am Coll Cardiol. 2002;40(1):111-118. doi:10.1016/S0735-1097(02)01932-0

33. Hernández-Madrid A, Lu X, Tsintzos SI, et al. Heart failure hospitalization reduction and cost savings achieved by improved delivery of effective biventricular pacing: economic implications of the OLE study under the US setting. Clinicoecon Outcomes Res. 2019;11:385-393. doi:10.2147/CEOR.S205501

34. Guo Y, Lip GYH, Banerjee A. Heart failure in East Asia. Curr Cardiol Rev. 2013;9(2):112-122.

35. Bundhamcharoen K, Aungkulanon S. Burden of Disease in Thai Population 2009. International Health Policy Program; 2012.

36. Health Statistics, Strategy and Planning Division, Ministry of Public Health. Mortality rate per 100,000 Thai population by causes of death during 1998-2016. 2016 [cited February 2, 2018]. Available from: http://social.nesdb.go.th/SocialStat/StatReport_Final.aspx?reportid= 441 \& template $=2 \mathrm{R} 1 \mathrm{C} \&$ yeartype $=\mathrm{M} \&$ subcatid $=15$.

37. Neyt M, Stroobandt S, Obyn C, et al. Cost-effectiveness of cardiac resynchronisation therapy for patients with moderate-to-severe heart failure: a lifetime Markov model. BMJ Open. 2011;1(2):e000276. doi:10.1136/bmjopen-2011-000276
ClinicoEconomics and Outcomes Research

\section{Publish your work in this journal}

ClinicoEconomics and Outcomes Research is an international, peerreviewed open-access journal focusing on Health Technology Assessment, Pharmacoeconomics and Outcomes Research in the areas of diagnosis, medical devices, and clinical, surgical and pharmacological intervention. The economic impact of health policy and health systems

\section{Dovepress}

organization also constitute important areas of coverage. The manuscript management system is completely online and includes a very quick and fair peer-review system, which is all easy to use. Visit http://www.dovepress.com/testimonials.php to read real quotes from published authors. 